\title{
Preferensi Konsumsi Kumbang Beras (Sitophilus Oryzae L) Pada Beberapa Varietas Beras)
}

\author{
Syamsul Rizal ${ }^{1 *}$, Dian Mutiara ${ }^{2}$, Dina Agustina ${ }^{3}$ \\ *e-mail: syamsul_rizal_msi@yahoo.com \\ ${ }^{1,2}$ Program Studi Biologi, Fakultas Matematika dan Ilmu Pengetahuan Alam \\ Universitas PGRI Palembang \\ ${ }^{2}$ Alumni Fakultas Matematika dan Ilmu Pengetahuan Alam Universitas PGRI Palembang
}

\begin{abstract}
Research on the Consumption Preference for Rice Beetles (Sitophilus oryzae L) in Several Rice Varieties was carried out from March to Mei 2019 at Laboratory Science Center of PGRI University. The study aims to determine the consumption preferences of several rice varieties caused by rice beetles. The study used the Experimental method in a completely randomized design (CRD) with five treatments and five replications, namely white, red, black, white sticky rice and black sticky rice varieties. Based on the analysis of fingerprints, the treatment of white sticky rice varieties significantly affected the amount of lose weight rice and rice beetle consumption preference, then continued with the BNT Test. The treatment of varieties D (white sticky rice) was not significantly different from the treatment of varieties E (black sticky rice), treatment $\mathrm{E}$ (black sticky rice) significantly different from the treatment of variety $\mathrm{C}$ (black rice), the treatment of variety $\mathrm{C}$ (black rice) was not significantly different from the treatment of variety B (brown rice), treatment of variety B (brown rice) was significantly different from the treatment of variety A (white rice). Based on the BNT Test, rice beetle consumption preferences seen from the weight reduction of rice in D rice varieties had the greatest weight reduction of 6.6 grams and the lowest weight reduction was white rice varieties of 0.9 grams, while for red, black and Black sticky rice has an average weight loss of rice each of 4.1 grams, 4.2 grams and 5.7 grams. Based on the percentage of preference (preference) for rice beetle consumption, it was found that the highest percentage was found in white sticky rice varieties at $6.6 \%$ and the lowest in white rice varieties at $1.5 \%$, while for brown rice varieties at $4 \%$, black rice $4.2 \%$ and black sticky rice $5.6 \%$.
\end{abstract}

Keywords: Preferences, rice beetles, white, red, black rice, white sticky rice and black sticky rice, rice beetles

\begin{abstract}
ABSTRAK
Penelitian tentang Preferensi Konsumsi Kumbang Beras (Sitophilus oryzae L) pada Beberapa Varietas Beras dilaksanakan dari bulan Maret sampai dengan bulan Mei 2019 di Laboratorium Terpadu Universitas PGRI Palembang. Penelitian bertujuan mengetahui Preferensi Konsumsi Beberapa Varietas Beras yang disebabkan oleh kumbang beras. Penelitian menggunakan metode Eksperimen dalam rancangan acak lengkap (RAL) dengan lima perlakuan dan lima ulangan, yaitu varietas beras putih, merah, hitam, ketan putih dan ketan hitam. Berdasarkan Analisis sidik ragam perlakuan varietas ketan putih berpengaruh nyata terhadap jumlah kehilangan bobot beras dan preferensi konsumsi kumbang beras maka dilanjutkan dengan Uji BNT maka didapatkan perlakuan varietas $\mathrm{D}$ (ketan putih) tidak berbeda nyata dengan perlakuan varietas E (ketan hitam), perlakuan E (ketan hitam) berbeda nyata dengan
\end{abstract}


perlakuan varietas $\mathrm{C}$ (beras hitam), perlakuan varietas $\mathrm{C}$ (beras hitam) tidak berbeda nyata dengan perlakuan varietas B (beras merah), perlakuan varietas B (beras merah) berbeda nyata dengan perlakuan varietas A (beras putih). Berdasarkan Uji BNT preferensi konsumsi kumbang beras yang dilihat dari pengurangan berat beras pada varietas beras $\mathrm{D}$ memiliki pengurangan berat paling besar yaitu sebesar 6,6 gram dan pengurangan bobot terendah adalah varietas beras putih sebesar 0,9 gram, sedangkan untuk varietas beras merah, hitam dan ketan hitam memiliki rata-rata kehilangan berat beras masing-masing sebesar 4,1 gram, 4,2 gram dan 5,7 gram. Berdasarkan persentase preferensi (kesukaan) konsumsi kumbang beras didapatkan bahwa persentase terbesar terdapat pada varietas ketan putih sebesar 6,6 \% dan terendah pada varietas beras putih sebesar $1,5 \%$, sedangkan untuk varietas beras merah sebesar $4 \%$, beras hitam 4,2 \% dan ketan hitam 5,6\%.

Kata Kunci: Preferensi, kumbang beras, beras putih, merah, hitam, ketan putih dan ketan hitam, kumbang beras.

\section{PENDAHULUAN}

Preferensi maksudnya (hak
untuk) didahulukan dan diutamakan daripada yang lain; prioritas; pilihan; kecenderungan; kesukaan (Kamus Besar Bahasa Indonesia, 2019). Kebutuhan beras di Indonesia mengalami peningkatan seiring dengan pertambahan jumlah penduduk. Pertambahan jumlah penduduk seiap tahun mengalami peningkatan secara signifikan sehingga peningkatan kebutuhan beras sebagai bahan makan pokok penduduk Indonesia khususnya dan Asia umumnya juga mengalami peningkatan. Produksi beras yang melimpah akan menimbulkan masalah hama pada tempat penyimpanan. Serangan hama pada saat penyimpanan dapat menimbulkan kerusakan pada beras dan menurunkan kualitas (Lihawa dan Toana, 2017)

Beras menjadi komoditas
strategis dalam perekonomian dan ketahanan pangan nasional, sehingga menjadi basis utama dalam revitalisasi pertanian. Untuk mencapai sasaran tersebut banyak kendala yang ditemui, salah satu diantaranya adalah faktor penanganan pascapanen yang tidak tepat. Proses penyimpanan beras digudang merupakan salah satu mata rantai pascapanen yang sangat penting (Hendrival dan Melinda, 2017)
Kumbang beras (Sitophilus Oryzae L), merupakan salah satu jenis serangga gudang yang banyak merusak persediaan beras di tempat penyimpanan. Serangga Sitophylus oryzae menyebabkan butiran beras menjadi berlobang kecil-kecil serta mudah pecah dan remuk bagaikan tepung, sehingga kualitasnya rendah karena rasanya tidak enak dan berbau apek. Kehadiran hama kumbang beras ini perlu dikendalikan dengan tepat, agar kualitas dan kuantitas beras dalam simpanan tidak menurun (Isnaini et al., 2015).

Penurunan kuantitas dan kualitas bahan pangan dapat terjadi selama penyimpanan di gudang yang disebabkan oleh serangan serangga hama. Iklim negara Indonesia yang panas dan lembab, merupakan kondisi yang sangat baik bagi pertumbuhan serangga hama, sehingga mempercepat proses deteriorasi. Beras yang disimpan di dalam gudang tradisional maupun gudang modern sering mendapat gangguan serangga hama sehingga menyebabkan terjadinya kerusakan dan kehilangan berat bahan. Besarnya kerusakan dan kehilangan berat beras tergantung dari cara serangga hama menyerang atau merusak. Apabila serangan serangga hama terus berlanjut maka terjadi penurunan mutu dan 
menyebabkan kontaminasi pada bahan pangan yang disimpan sehingga tidak layak untuk dikonsumsi (Lopulalan, 2010).

Kepadatan populasi hama berhubungan erat dengan besarnya kerusakan yang ditimbulkan. Hama bahan simpan umumnya merupakan hama langsung, yang artinya kerusakan terjadi langsung pada bahan yang di konsumsi. 5-15\% kerusakan diantaranya disebabkan oleh Sitophilus oryzae L. (Susanti et al., 2017). Kerusakan bahan pangan yang terjadi selama penyimpanan adalah kerusakan fisik, kimia, mekanik, biologi dan mikrobiologi yang akan menurunkan mutu hasil pertanian secara kualitatif maupun kuantitatif. Penyebab kerusakan saat pasca panen yang paling sering terjadi karena serangan hama pascapanen (Lopulalan, 2010).

Menurut Kurniawan (2013) perbedaan biji-bijian mungkin menyebabkan perbedaan mutu gizi, dan akan memberi pengaruh yang berlainan pada pertumbuhan dan perkembangan populasi serangga. Indikator terhadap preferensi serangga pada biji-bijian ditentukan oleh jumlah telur yang diletakkan oleh induk betina, jumlah telur yang menetas menjadi imago, dan lama daur hidup. Makin besar jumlah telur yang diletakkan dan makin banyak imago yang terbentuk serta semakin pendek daur hidupnya menunjukkan preferensi serangga pada biji makin besar. Pada bijibijan yang lebih disukai olah Sitophilus oryzae, tingkat kerusakan yang ditimbulkan menunjukkan hubungan yang linier.

Kutu beras adalah nama umum dari serangga kecil anggota genus Sitophilus yang hidup pada biji-bijian yang disimpan. Serangga ini menyerang dan memakan gabah atau beras yang disimpan didalam gudang penyimpanan, selain itu serangga ini juga menyerang bulir jagung, berbagai jenis gandum, jewawut, sorgum, serta biji kacang- kacangan. Larvanya bersarang didalam bulir/biji, sedangkan imagonya memakan tepung yang ada. Kumbang beras (Sitophilus oryzae L.), merupakan salah satu jenis serangga hama gudang yang merusak persediaan beras di tempat penyimpanan yang merupakan salah satu komponen yang merugikan, baik secara kuantitas maupun kualitas. Kutu beras menyebabkan butiran beras menjadi berlobang kecil-kecil serta mudah pecah dan remuk bagaikan tepung, sehingga kualitasnya rendah karena rasanya tidak enak dan berbau apek. Butiran beras hancur dan berdebu, dalam waktu yang cukup singkat. Serangan hama dapat mengakibatkan perkembangan jamur, sehingga produksi beras rusak, bau apek yang tidak enak dan tidak dapat dikonsumsi (Isnaini et al., 2015).

Menurut Philips dan Throne, (2010) kerusakan yang disebabkan oleh kumbang beras (Sitophilus oryzae L.) berkisar antara 10-20\% dari keseluruhan produksi. Menurut Haryadi (2010) kerusakan hama dapat menimbulkan kehilangan bobot, komponen pangan (nilai nutrisi), sifat fungsional bahan pangan, mutu, benih, nilai uang, kepercayaan dan kesempatan. Sitophilus oryzae dapat mengkonsumsi beras sampai $0.49 \mathrm{mg}$ per hari. Hilangnya nilai nutrisi dan sifat fungsional dari bahan pangan pun, akan menghilangkan tingkat kepercayaan konsumen dari segi ekonomis. Jika kualitas dan kuantitas beras yang diperjualbelikan oleh produsen, termasuk kualitas bawah, maka produk yang akan dihasilkan juga akan menurun kualitasnya. Secara ekonomi, kerugian akibat serangan hama adalah turunnya harga jual komoditas bahan pangan (biji-bijian).

Kerugian akibat serangan serangga hama dari segi ekologi atau lingkungan adalah adanya ledakan populasi serangga yang tidak terkontrol. Selama ini penelitian tentang kumbang beras hanya terfokus pada tingkat konsumsi larva kumbang 
beras saja. Penelitian yang ada selama ini hanya pada jenis beras putih saja, sedangkan untuk jenis-jenis beras yang lain masih sangat sedikit. Untuk itu perlu dilakukan penelitian terhadap beberapa jenis beras yang meliputi beras putih, merah, hitam, ketan putih dan ketan hitam.

\section{BAHAN DAN METODE}

Penelitian ini dilaksanakan pada bulan Maret 2019 sampai dengan Mei 2019 di Laboratorium Biologi Fakultas MIPA Universitas PGRI Palembang. Adapun alat yang digunakan dalam penelitian ini adalah timbangan digital, toples besar $10 \mathrm{~L}$, toples kecil dengan ukuran $7 \times 8 \mathrm{~cm}$, pinset, cawan petri, baskom, label kertas, alat tulis, plastik hitam, dan kamera handphone. Bahan yang digunakan adalah kutu beras (Sitophilus oryzae L), beras putih, merah, hitam, ketan putih, dan ketan hitam. Penelitian ini menggunakan Metode Eksperimen dengan Rancangan Acak Lengkap dengan 5 perlakuan dan 5 ulangan.

\section{Penyiapan Serangga Kumbang Beras (Sitophilus oryzae L)}

Penyiapan

seranggga

dimaksudkan agar pada saat pelaksanaan percobaan sudah tersedia stok serangga uji yang cukup dan umur serangga yang seragam. Kumbang beras sebanyak 50 ekor jantan, 50 ekor betina dan beras yang telah teridentifikasi kumbang beras dibawa ke Laboratorium Biologi Fakultas MIPA. Selanjutnya isi toples yang berukuran $10 \mathrm{~L}$ dengan beras sebanyak 4 $\mathrm{kg}$ dan masukkan kumbang beras yang telah disiapkan kedalam toples. Lalu didiamkan selama 2-3 bulan untuk mendapatkan keturunan ketiga (F3).
Siapkan sampel beras yang belum terindikasi kumbang beras. Sampel beras yang digunakan meliputi beras putih yang merupakan jenis beras anorganik dan beras merah, hitam, ketan putih dan ketan hitam merupakan jenis beras organik. Beras pada setiap perlakuan ditimbang sebanyak 100 gram yang dimasukkan kedalam toples berukuran $7 \times 8 \mathrm{~cm}$.

\section{Uji Preferensi}

Dilubangi setiap tutup toples yang telah di isi dengan beras sebelumnya sebanyak 20 lubang. Lalu pilihlah serangga hama kumbang beras (Sitophilus oryzae L.) yang cukup dan memiliki umur yang seragam sebanyak 250 ekor, kemudian letakkan kumbang beras yang telah dipilih kedalam cawan petri dan timbanglah setiap 10 ekor kumbang beras menggunakan timbangan dan masukkan serangga hama kumbang beras kedalam masing-masing toples yang telah terisi masing-masing beras, lalu tutuplah toples dengan rapat agar serangga dari luar tidak bisa masuk kedalam toples. Bungkuslah toples menggunakan plastik hitam, letakkan diatas meja dan berilah label masingmasing toples.

\section{Pengamatan}

Tingkat konsumsi dapat dilihat dari hilangnya bagian atau berkurangnya berat atau penyusutan berat pada setiap jenis beras. Susut berat adalah berkurangnya berat bahan akibat dimakan atau diserang oleh serangga hama. Perhitungan persentase preferensi menggunakan rumus berikut:

Persentase preferensi $=\{$ Berat beras awal (g) - Berat beras akhir (g)\} x 100\%

\section{Persiapan Media Beras}


Data yang diperoleh dianalisis dengan Analisis Sidik Ragam (Ansira). Bila berpengaruh nyata, maka dilanjutkan dengan uji beda nyata terkecil (BNT).
Hasil penelitian yang dilakukan selama 45 hari tentang Preferensi Konsumsi pada beberapa Varietas Beras didapatkan data seperti pada Tabel 1.

\section{HASIL DAN PEMBAHASAN}

Tabel 1. Penyusutan berat beras dan persentase preferensi akibat kumbang beras (Sitophilus oryzae L.) terhadap beberapa varietas beras.

\begin{tabular}{cclc}
\hline Perlakuan & Berat Beras Akhir & $\begin{array}{c}\text { Rata-rata Penyusutan } \\
\text { Berat Beras }\end{array}$ & $\begin{array}{c}\text { Persentase } \\
\text { Preferensi (\%) }\end{array}$ \\
\hline P1 (Beras Putih) & $492,4 \mathrm{~g}$ & $=>4,4 / 5=0,9$ gram & $1,5 \%$ \\
P2 (Beras Merah) & $480 \mathrm{~g}$ & $=>20,4 / 5=4,1$ gram & $4 \%$ \\
P3 (Beras Hitam) & $479,1 \mathrm{~g}$ & $=>21,2 / 5=4,2$ gram & $4,2 \%$ \\
P4 (Ketan Putih) & $466,9 \mathrm{~g}$ & $=>33,2 / 5=6,6$ gram & $6,6 \%$ \\
P5 (Ketan Hitam) & $472 \mathrm{~g}$ & $=>28,3 / 5=5,7$ gram & $5,6 \%$
\end{tabular}

Berdasarkan Analisis Sidik Ragam, preferensi konsumsi kumbang beras pada 5 varietas beras berpengaruh sangat nyata terhadap persentase preferensi konsumsi kumbang beras.

Tabel 2. Hasil Analisis Sidik Ragam pada parameter pengamatan

\begin{tabular}{lccccc}
\hline $\begin{array}{c}\text { Sumber } \\
\text { Keragaman } \\
(\mathrm{SK})\end{array}$ & $\begin{array}{c}\text { Derajat } \\
\text { Bebas } \\
(\mathrm{DB})\end{array}$ & $\begin{array}{c}\text { Jumlah } \\
\text { Kuadrat }(\mathrm{JK})\end{array}$ & $\begin{array}{c}\text { Kuadrat } \\
\text { Tengah }(\mathrm{KT})\end{array}$ & Fhitung & $\begin{array}{c}\text { Ftabel } \\
5 \%\end{array}$ \\
\hline Perlakuan & 4 & 74,35 & 18,59 & $7,21^{* *}$ & 2,87 \\
Error $(\mathrm{g})$ & 20 & 51,64 & 2,58 & & \\
\hline Total & 24 & 125,99 & & \\
\hline Keterangan : * $=$ berbeda nyata \\
$\mathrm{t}^{\mathrm{n}}=$ tidak nyata
\end{tabular}

Bila dibandingkan yaitu $7,21>$ 2,87. Maka dapat dikatakan preferensi konsumsi kumbang beras berpengaruh sangat nyata terhadap perbedaan varietas beras yang digunakan maka dilanjutkan dengan Beda Nyata Terkecil (BNT) seperti pada (tabel 4) 
Tabel 4. Hasil uji BNT pada parameter rata-rata jumlah preferensi konsumsi kumbang beras pada setiap varietas beras

\begin{tabular}{|ccc|}
\hline No. & Perlakuan & $\begin{array}{c}\text { Jumlah rata-rata preferensi } \\
\text { konsumsi kumbang beras (gram) }\end{array}$ \\
\hline 1 & A & $0,9 \mathrm{c}$ \\
2 & $\mathrm{~B}$ & $4,1 \mathrm{~b}$ \\
3 & $\mathrm{C}$ & $4,2 \mathrm{~b}$ \\
4 & $\mathrm{D}$ & $6,6 \mathrm{a}$ \\
5 & $\mathrm{E}$ & $5,7 \mathrm{a}$ \\
\hline
\end{tabular}

Keterangan : Angka yang diikuti huruf yang sama pada kolom yang sama berbeda tidak nyata pada Uji BNT taraf 0,05\%.

Hasil penelitian tentang preferensi konsumsi kumbang beras pada 5 varietas beras menunjukkan bahwa rata-rata persentase preferensi kehilangan berat beras dari yang terbesar sampai yang terkecil yaitu pada ketan putih 6,6\%, ketan hitam sebesar 5,6\%, beras hitam sebesar $4,2 \%$, beras merah sebesar $4 \%$, dan beras putih sebesar 1,5\% dan dapat dilihat pada Tabel 2.

Berdasarkan hasil analisis sidik ragam konsumsi kumbang beras (Sitophilus oryzae L.) pada 5 varietas beras menunjukkan bahwa kesukaan pada beras yang diakibatkan oleh kumbang beras berpengaruh nyata terhadap kehilangan berat beras (Tabel 3) sehingga dilakukan Uji Lanjut BNT. Hasil penelitian menunjukkan bahwa perbedaan varietas beras mempengaruhi jumlah kehilangan berat dan beras berlubang akibat serangan kumbang beras.

Perbedaan dari penyusutan berat pada setiap perlakuan dapat disebabkan oleh ketidaksesuaian beras seperti butiran beras yang terlalu keras atau kandungan nutrisi di dalam beras yang kurang sesuai. Menurut Ashamo, (2006) serangga dewasa dan larva kumbang beras akan merusak biji-bijian dengan memakan karbohidrat dalam butiran biji sehingga terjadi penurunan susut berat pangan dan kontaminasi produk, mengurangi viabilitas benih, menurunkan nilai pasar, dan mengurangi nilai gizi.
Hasil analisis ragam menunjukkan bahwa preferensi konsumsi kumbang beras berpengaruh sangat nyata terhadap kehilangan berat pada setiap perlakuan. Penyusutan berat paling besar terdapat pada beras ketan putih yang mengalami penyusutan sebesar 6,6 gram dan persentase preferensi yang paling rendah yaitu sebesar 1,5\%, penyusutan ini terjadi diakibatkan dari karakteristik dari beras ketan putih yang memiliki tekstur beras lebih lembut dibandingkan dengan tekstur beras pada varietas lain sehingga mempengaruhi persentase preferensi konsumsi yang dihasilkan. Menurut Yasin (2009), secara alami serangga hama akan mampu memilih sumber makanan yang disenangi. Serangga akan mempunyai suatu kecenderungan tertentu dalam mengakses sumber makanannya. Perbedaan dalam hal tekstur dan struktur, jenis varietas dan komposisi kimia yang terkandung dalam beras akan berpengaruh besar pada sifat prefensi komsumsi.

Menurut Koswara (2009), beras biasa dan beras ketan memiliki perbedaan baik secara fisik dan kandungan senyawanya. Beras biasa memiliki tekstur lebih keras dibandingkan tekstur beras ketan yang lebih rapuh, warna dari beras biasa putih cemerlang sedangkan beras ketan memiliki warna buram putih seperti kapur dan memiliki ukuran besar dari beras biasa yang menyebabkan penyusutan ketan putih lebih tinggi. 
Kandungan karbohidrat didalam beras biasa sebesar $79 \mathrm{~g}$ dan didalam beras ketan sebesar 81,68 g. Karena kandungan karbohidrat didalam ketan putih lebih tinggi menyebabkan penyusutan bobot beras dan preferesi konsumsi pada ketan putih pun tinggi.

Tekstur ketan hitam yang hampir sama dengan ketan putih membuat ketan hitam mengalami penyusutan berat yang lebih banyak dari beras putih, merah dan hitam. Walaupun kandungan karbohidrat didalam ketan hitam sebesar 74,5 g lebih rendah dibandingkan varietas beras lain, karena tekstur beras yang rapuh membuah kumbang beras lebih mudah untuk melakukan penggerekan.

Kandungan karbohidrat didalam beras hitam sebesar 76, $9 \mathrm{~g}$ yang lebih tinggi dibandingkan dengan beras merah sebesar 76,2 g menyebabkan persentase preferensi konsumsi pada beras hitam lebih tinggi dibandingkan beras merah.

Menurut Fara et al. (2005), tersedianya pakan yang cukup dan cocok bagi kehidupan kumbang beras menyebabkan populasi hama akan meningkat.

Kandungan karbohidrat didalam beras merah sebesar 76, $2 \mathrm{~g}$ yang lebih rendah dibandingkan dengan beras putih sebesar 77,1 g tidak mempengaruhi persentase preferensi konsumsi pada beras merah, hal ini terjadi karena adanya indikasi zat kimia didalam beras putih yang menyebabkan kumbang beras sukar untuk mengkonsumsi beras putih.

Dari kesemua varietas beras yang diujikan beras putih merupakan varietas beras yang mengalami kekurangan bobot dan kerusakan beras paling sedikit. Walaupun kandungan karbohidrat didalam beras putih paling besar setelah ketan putih akan tetapi preferensi konsumsi pada beras putih merupakan yang terendah. Hal ini terjadi karena beras putih yang diujikan diduga terdapat zat kimia yang mempengaruhi preferensi konsumsi yang dapat mengganggu peletakkan telur dan permukaannya lebih licin, sehingga imago betina kumbang beras tidak suka untuk bertelur. Sedangkan untuk 4 varietas beras lain merupakan varietas beras organik yang sangat sangat rentan terhadap serangan hama gudang. Hasil penelitian yang sama juga dilaporkan oleh Harinta (2016) bahwa rata-rata jumlah telur yang menetas menjadi imago, dapat diketahui pada beras hitam lebih tinggi dari pada perlakuan beras yang lain (beras merah dan putih).

Preferensi dan jumlah populasi kumbang beras pada pada beras dapat menjadi penanda bahwa beras yang disimpan mengandung pestisida atau tidak. Karena beras yang mengandung pestisida tidak disukai oleh kumbang beras dan sebaliknya jika beras tidak mengandung pestisida maka kumbang beras akan sangat suka dan menimbulkan kerusakan yang besar. Semakin banyak bobot beras yang menyusut menandakan bahwa tingkat kesukaan kumbang beras terhadap beras tersebut tinggi, dan sebaliknya semakin rendah tingkat kesukaan kumbang beras pada varietas beras maka tingkat kerusakannya rendah. Hal ini sesuai dengan pendapat Kardiman A. (2005), yang menyatakan bahwa residu pestisida bagi serangga hama bersifat racun perut yang bisa mengakibatkan serangga hama mati.

\section{KESIMPULAN}

Dapat disimpulkan bahwa Varietas beras merah, hitam dan ketan hitam dapat menyebabkan penyusutan berat beras sebesar 4,1 gram, 4,2 gram dan 5,7 gram. Beras putih merupakan varietas beras yang terendah dalam penyusutan berat beras yaitu sebesar 0,9 gram dan penyusutan berat beras yang paling besar adalah ketan putih sebesar 6,6 gram. Pada setiap varietas beras memiliki persentase preferensi yang berbeda-beda, yaitu pada varietas beras 
putih sebesar $1,5 \%$, beras merah $4 \%$, beras hitam $4,2 \%$, ketan putih $6,6 \%$ dan ketan hitam sebesar 5,7\%. Semakin banyak penyusutan berat beras maka semakin besar persentase preferensi konsumsi kumbang beras yang terjadi.

\section{DAFTAR PUSTAKA}

Ashamo MO. 2006. Relative susceptibility of some local and elite rice varieties to the rice weevil, Sitophilus oryzae L. (Coleoptera: Curculionidae). Journal of Food, Agriculture \& Environment 4(1): 249-252.

Fara, S. B., Pelealu, J. dan Mamahit, J. M. E. 2016. Mortalitas Sitophilus oryzae L. pada Beras Suluttan Unsrat, Ketan Putih, dan Beras Merah di Sulawesi Utara. Jurnal Bioslogos Vol. 6 No. 1.

Harinta, Y., W. 2016. Uji Ketahanan Beberapa Jenis Beras (Oryza sativa) Terhadap Hama Kumbang Bubuk Beras (Sitophilus oryzae). Agrovigor Volume 9 No. 2, ISSN 1979 5777.

Haryadi, Y. 2010. Peranan Penyimpanan Dalam Menunjang Ketahanan Pangan. Bogor: Artikel Departemen Ilmu dan Teknologi Pangan Institut Pertanian Bogor.

Hendrival dan Melinda, L. 2017. Pengaruh Kepadatan Populasi Sitophilus oryzae (L.) terhadap Pertumbuhan Populasi dan Kerusakan Beras. Biospecies Vol. 10 No. 1.

Isnaini, M. Pane, E. R. dan Wiridianti, S. 2015. Pengujian Beberapa Jenis Insektisida Nabati Terhadap
Kutu Beras (Sitophilus oryzae L). Jurnal Biota Vol.1 No.1.

Kamus Besar Bahasa Indonesia. 2019. Preferensi. https://kbbi.web.id. Diakses pada tanggal 22 Juli 2019.

Kardiman A., 2005. Pestisida Nabati, Kemampuan dan Aplikasi. Jakarta: Penebar Swadaya.

Koswara, S. 2009. Teknologi Pengolahan Beras. www.eBookPangan.com. Diakses pada tanggal 23 Juni 2019.

Kurniawan, D. 2013. Preferensi Sitophilus oryzae Terhadap Beberapa Jenis Beras Serta Evaluasi Kesehatan Benih Jagung Dan Kedelai Terhadap Patogen Benih. Malang: Universitas Brawijaya.

Lihawa, Z., dan Toana, M., H. 2017. Pengaruh Konsentrasi Serbuk Majemuk Biji Sarikaya Dan Biji Sirsak Terhadap Mortalitas Kumbang Beras Sitophilus Oryzae L. (Coleoptera : Curculionidae) Di Penyimpanan. e-J. Agrotekbis 5 (2) : 190 - 195, ISSN : 23383011 .

Lopulalan, CGC. 2010. Analisa ketahanan beberapa varietas padi terhadap serangan hama gudang (Sitophilus zeamais Motschulsky). Jurnal Budidaya Pertanian. vol 6(1): 11-16.

Phillips TW and Throne JE. 2010. Biorational approaches to managing stored product. Annual Review of Entomology. vol 55: 375-397. 
Preferensi Konsumsi Kumbang...,Syamsul R, Dian M., dan Dina A.,..Sainmatika,...Volume 16,...No.2,...Desember $2019, \ldots 157-165$

Susanti, Yunus, M. dan Pasaru, F. 2017. Efektifitas Ekstrak Daun Pandan Wangi (Pandanus amaryllifolius roxb) terhadap Kumbang Beras (Sitophylus oryzae L.). Jurnal Agroland 24 (3) : $208-213$.

Yasin, M. 2009. Kemampuan Akses Makan Serangga Hama Kumbang Bubuk Dan Faktor Fisikokimia Yang Mempengaruhinya. Balai Penelitian Tanaman Serealia. ISBN :978-979-894. 